\title{
Implementation of CSR in the organizations'strategies: experience of Russia and Belarus, directions of methods and tools development of CSR in the conditions of digitalization of economies
}

\author{
Galina Yaheva ${ }^{1, *}$, Andrey Plakhin ${ }^{2}$, Yulia Vailunova $^{1}$, and Maria Selezneva $^{2}$ \\ ${ }^{1}$ Vitebsk State Technological University, 210035 Vitebsk, Republic of Belarus \\ ${ }^{2}$ Ural State University of Economics, 620144 Ekaterinburg, Russia
}

\begin{abstract}
The purpose of the article is to analyze the experience of introducing CSR in the Union State of Russia and Belarus and to develop directions for the development of CSR methods and tools in the context of the digitalization of the economies of Russia and Belarus.The article systematizes methods for assessing CSR at the macro and micro levels: compliance with international CSR standards; involvement in the UN Global Compact; indices for assessing the effectiveness of companies in the field of CSR; ratings and indices for assessing the effectiveness of CSR, developed by public and state organizations. The analysis of the experience of CSR implementation in the Union State of Russia and the Republic of Belarus is carried out. Identified barriers to the development of CSR in Russia and the Republic of Belarus. The directions of development of CSR methods and tools in the context of digitalization of the economies of Russia and Belarus are studied. Scientific significance lies in the development of CSR methods and tools in the context of digitalization of economies. The study used modern scientific literature on the digital ecosystem and CSR, statistical and analytical materials found on thematic Internet sites and in print media. The practical significance of the results lies in the possibility of their use by state and regional authorities, business in CSR strategies, as an integral part of the strategy for sustainable development of the economy, for making decisions aimed at increasing the stability and competitiveness of the economies of the Union State.
\end{abstract}

\section{Introduction}

The establishment of the institution of corporate social responsibility (CSR) took place in the 70 s of the last century, when leading companies in the West, trying to protect their reputation from anti-corporate-minded social groups, began to declare their responsibility to society. Currently CSR helps to improve the company's image in the eyes of consumers, partners, and society as a whole. Thus, according to the McKinsey report, $78 \%$ of the

\footnotetext{
*Corresponding author: gala-ya@list.ru
} 
experts they interviewed, say that CSR activities improve the company's image. According to a CONE study, $53 \%$ of shoppers say a company's CSR is an important factor when choosing a product. In a Deloitte study, $38 \%$ of CEOs claim that CSR increases employee loyalty [1].

Thus, CSR contributes to sustainable development, including the health and well-being of society; takes into account the interests of various stakeholders; complies with applicable law and is consistent with international norms of behavior; integrated into the activities of the entire organization and applied in its relationships.

An organization's overarching goal of social responsibility should be seen as contributing to sustainable development, the goal of which is to achieve the sustainability of society as a whole. It is with the implementation of the CSR concept that the goals of sustainable development can be achieved in the new realities.

The peculiarity of the external environment is the active development of information and computer technologies and their implementation in various fields of activity. The COVID-19 epidemic, the difficult economic situation (falling GDP in all countries) are reflected in the CSR projects of organizations, including Russia and the Republic of Belarus. This circumstance creates an opportunity to use digitalization tools to stimulate CSR strategies, which determines the relevance of the topic of this study.

The purpose of the article is to analyze the experience of introducing CSR in the Union State of Russia and Belarus and to develop directions for the development of CSR methods and tools in the context of the digitalization of the economies of Russia and Belarus.

Based on the goal, the following tasks have been identified:

- Systematization of methods for assessing CSR at the macro and micro levels;

- Analysis of CSR implementation experience in Russia and Belarus and identification of barriers to CSR development;

- Study of directions for the development of CSR methods and tools in the context of digitalization of the economies of Russia and Belarus.

\section{Materials and Methods}

The theoretical and methodological basis of the study is the scientific works of foreign researchers that had a significant impact on the formation of the foundations of social management: F. Taylor (school of scientific management), the ideas of M. Weber, A. Fayol (school of administrative management), E. Mayo (school of human relations ), the behavioral school (A. Maslow, K. Aldarfer, F. Herzberg, D. McGregor), the theory of loyalty and fair treatment of an employee by R. Husman and J. Hetfield, consideration of CSR as an element of corporate culture (ideas of E. Shane), the theory of investment in human capital by G. Becker and T. Schultz. The ideological origins of the modern concept of CSR in the theory of G. Bowen, M. Friedman (the theory of corporate egoism), A. Kerrol (the pyramid of CSR levels), E. Freeman (the theory of stakeholders) are also considered.

Many scientific works are devoted to the study of the necessary degree of social responsibility of business, where the problems of responsible behavior of enterprises have been studied for a long time. Thus, the works of A. Burleigh, G. Bowen, A. Caroll, J. McGuire, G. Means, M. Friedman, E. Freeman and others played an important role in the development of the concept of CSR. In the scientific literature of researchers from the Union State of Russia and Belarus, the issues of corporate social responsibility are covered to a lesser extent, however, there are works of such researchers as Yu. Blagov, I. Belyaeva, M. A. Eskander, G. Tulchinsky, E. Wittenberg, A. Kostin, S. Peregudov, Y. Petrunin, V. Purlik, I. Semenenko. A special role is also played by the research of international 
organizations in the development of new approaches to CSR and the formation of standards for social reporting of business, including the UN, UNESKO, the World Bank and others.

The study used modern scientific domestic and foreign literature on the digital ecosystem and CSR, statistical and analytical materials found on thematic Internet sites and in print media. The main methods of study are empirical and theoretical: observation, comparison, graphical, statistical and econometric analysis.

\section{Results and Discussion}

\subsection{CSR assessment at macro and micro levels}

CSR of business is a concept that reflects the voluntary contribution of business to the development of society in the social, economic, environmental spheres, aimed at improving the standard of living of society and protecting the environment. The concept of stakeholders forms the basis of CSR, since the main goal of any business is to satisfy the interests of a wide range of interested groups. According to the studies [2-6], the main priorities of CSR organizations in Russia and Belarus are usually stated as follows:

- Production of high-quality and competitive products;

- Compliance with standards and laws;

- Payment of taxes;

- Introduction of mechanisms against environmental pollution;

- Implementation of measures to take care of the employees of the organization.

Thus, the CSR strategy becomes part of the sustainable development strategy of the entire economic system. It is quite obvious that in order for the system to develop steadily, it is necessary to ensure a balance of interests of different interested groupsor stakeholders. If it is a macroeconomic system, then not only the state, but also international organizations, business, public associations, the population and other stakeholders should be interested and act in its sustainable development. If this is a microeconomic system, then, consequently, it is important to take into account the interests of not only company shareholders, but also investors, representatives of state authorities, personnel, suppliers and consumers of products, local communities and non-profit organizations (NPOs).

The analysis and systematization of methods and tools for assessing CSR available in science and practice made it possible to identify the following methods for measuring involvement in CSR.

1. Method - Compliance with recognized international CSR standards (table 1), which include the following [7]:

- SA8000 (Social Accountability 8000) - a standard for assessing the social aspects of management systems. In Russia, only a few enterprises have been certified for compliance with SA800 (those who are part of the supply chain of European companies that require such a certificate);

- AA1000SES. The leading format for non-financial reporting on CSR is the AA1000 Stakeholders Engagement Standard, created by the Institute of Social and Ethical Accountability. The Russian version of the standard has been prepared by the Institute for Urban Economics Foundation, taking into account broad world practice. At present, the AA1000SES standard in Russia has been successfully implemented by more than 30 leading companies; 
Table 1. Interrelation of international, Russian and Belarusian CSR standards.

\begin{tabular}{|c|c|c|}
\hline International Standards & Russian Standard & Belarusian Standard \\
\hline ISO 26000 & \multirow[t]{2}{*}{ IC CSR-08260008000 } & \multirow{4}{*}{$\begin{array}{l}\text { Most of the social reports are } \\
\text { compiled according to } \\
\text { international standards AA1000 } \\
\text { and GRI, in short form they } \\
\text { contain two sections: "internal } \\
\text { corporate responsibility" and } \\
\text { "social investments" }\end{array}$} \\
\hline SA8000 & & \\
\hline GRI & $\begin{array}{c}\text { Basic indicators of the Russian } \\
\text { Union of Industrialists and } \\
\text { Entrepreneurs }\end{array}$ & \\
\hline AA1000SES & None & \\
\hline None & $\begin{array}{c}\text { Social Reporting Standard of } \\
\text { the Chamber of Commerce and } \\
\text { Industry }\end{array}$ & None \\
\hline
\end{tabular}

Source: compiled by the authors based on $[1,3,7]$

- GRI - the Global Reporting Initiative standard is based on the concept of sustainable business development, in which companies need to balance economic, environmental and social activities;

- ISO 26000 "Guidelines for social responsibility" - a standard in the development of which experts from Russia also took part, provides a guide on the principles, main themes and problems underlying social responsibility, ways of integrating socially responsible behavior into strategies, practices and organization processes.

In the Republic of Belarus and Russia, CSR reporting is not mandatory (only about $16 \%$ of companies keep reporting [1], therefore it is difficult to carry out a statistical analysis of the share of enterprises and organizations certified according to CSR standards).

2. Method - Involvement in the UN Global Compact, which was founded in 2000 and is one of the largest CSR initiatives in the world. Today the UN Global Compact unites more than 10 thousand companies and about 3 thousand non-profit organizations from more than 160 countries of the world [8].

Since 2006, the Republic of Belarus has started the processes of joining the UN Global Compact by those companies that seek to improve their public image, and by now more than 70 Belarusian organizations have joined the UN Global Compact [8].

The Russian network of the UN Global Compact was created in 2008 and currently includes 74 organizations [9]. At the same time, it is quite obvious that the assessment of the degree of organizations' involvement in CSR can be assessed by the share of organizations that are members of this Global Compact. Although these statistics do not provide an assessment of the effectiveness and efficiency of organizations in the field of CSR.

3. Method - Indexes for assessing the effectiveness of companies in the field of CSR. Currently, scientists offer various approaches to calculating certain indices in the field of CSR [10-13]. However, none of the considered indices aggregated the information in such a way that it was possible to determine the level of sustainable development not only of individual companies, but also of the country in which they operate. In addition, the calculation of the indices themselves is rather difficult due to the complexity and lack of mandatory statistical reporting.

4. Method - Ratings and indices for assessing the effectiveness of CSR, developed by public and state organizations.

The following ratings are used in the Republic of Belarus:

- A socially responsible brand. This indicator was developed within the framework of the USAID project in 2005 and is used in the "Brand of the Year" competition [2];

- The Goodness Index. Developed by the Belarusian Foundation of Goodness, which is the official representative of the UN Global Compact in Belarus since 2017 [14]. As part of the calculation of this index, business is evaluated in the following areas: 
- Labor practices and human rights;

- Good business practices;

- Consumer welfare and community participation;

- Environment.

The Goodness Index consists of a total of 134 indicators characterizing the four areas of corporate sustainability mentioned above. The result of the Index for each of the directions can be in the range from 0 to 3 points, and the overall indicator of the Index is the sum of indicators in the directions and can be in the range from 0 to 12 [14].

In Russia, to assess the activities of organizations in the field of CSR, are used indices on sustainable development of the Russian Union of Industrialists and Entrepreneurs, such as the Responsibility and Openness Index - the information disclosure index (to what extent the volume and quality of information in public corporate reporting of the largest Russian companies reflect the impact of companies on the social and the natural environment), and the Sustainable Development Vector Index (2015), which allows to assess what the environmental "price" of production is and how much social benefits are provided [3]. The Sustainable Development Vector Index consists of indicators such as wages and social support of staff, staff turnover, injury rate, staff training, investments in communities, energy consumption and energy efficiency, impact on water sources, air emissions, including greenhouse gas emissions, waste generation and handling [3].

The analysis of methods and tools for assessing CSR available in science and practice allowed us to conclude that there is no generally accepted method for assessing the involvement of organizations in CSR and assessing the effectiveness of organizations in the field of CSR. Therefore, to analyze the level of CSR of business in the Republic of Belarus and Russia, the results of studies with methods and tools comparable in the countries of the Union State will be used.

\subsection{Analysis of the experience of CSR implementation in the Union State of Russia and Belarus and identification of barriers to CSR development.}

The methodological basis of the study was the statement on the differentiation of CSR strategy at the macro and micro levels.

The quantitative assessment of CSR at the macro level is proposed by the consulting company "CIVITTA" [1], and includes 3 stages:

1. Determination of key indicators and degree of significance: ISO $14001(0.25)$, ISO 45001 (0.25), SA 8000 (0.5), Global Reporting Initiative (1), Global Compact (1), Carbon Disclosure Project (1);

2. Collecting information on the number of organizations certified and supporting initiatives, separately by country;

3. Calculation of the index of each country according to the formula 1 [1].

$$
\text { CSR index of country } A=\sum_{i=1}^{6} \frac{\frac{\text { number of companies in indicator i of country } A}{\text { total number of companies in indicator } i}}{\frac{\text { GDP at purchasing power parity in country } A}{\text { Worldwide GDP at purchasing power parity }}}
$$

Where: GDP - Gross domestic product

The results of the assessment carried out by the consulting company CIVITTA are presented in Figure 1. 


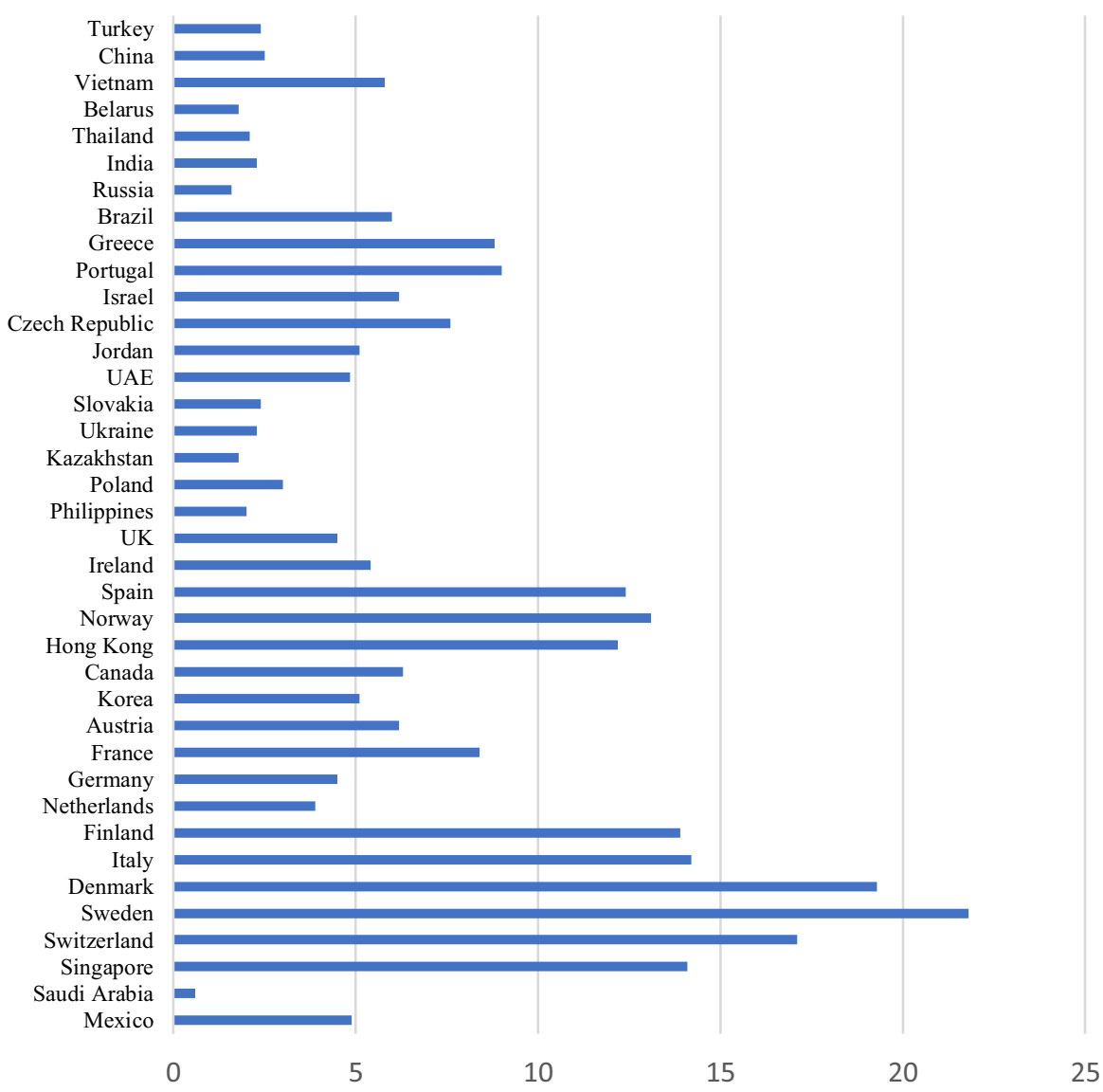

Fig. 1. CSR development index [1].

As can be seen in the graph, in general, the development of social responsibility of business in Russia and the Republic of Belarus is rather slow and lags significantly behind the developed best practices of Western countries. CSR leaders are Sweden, Finland, Great Britain. The Republic of Belarus has an estimate of 1.8, Russia - 1.6. The deviation from the national average CSR level is 14.9.

To study the factors influencing CSR, an analysis of the relationship between GDP and the CSR index was carried out. The results are shown in Figure 2.

The study has shown that there is a direct relationship between the CSR development level index and GDP per capita. Therefore, it is possible to formulate a hypothesis that the development of CSR is required for GDP growth. 


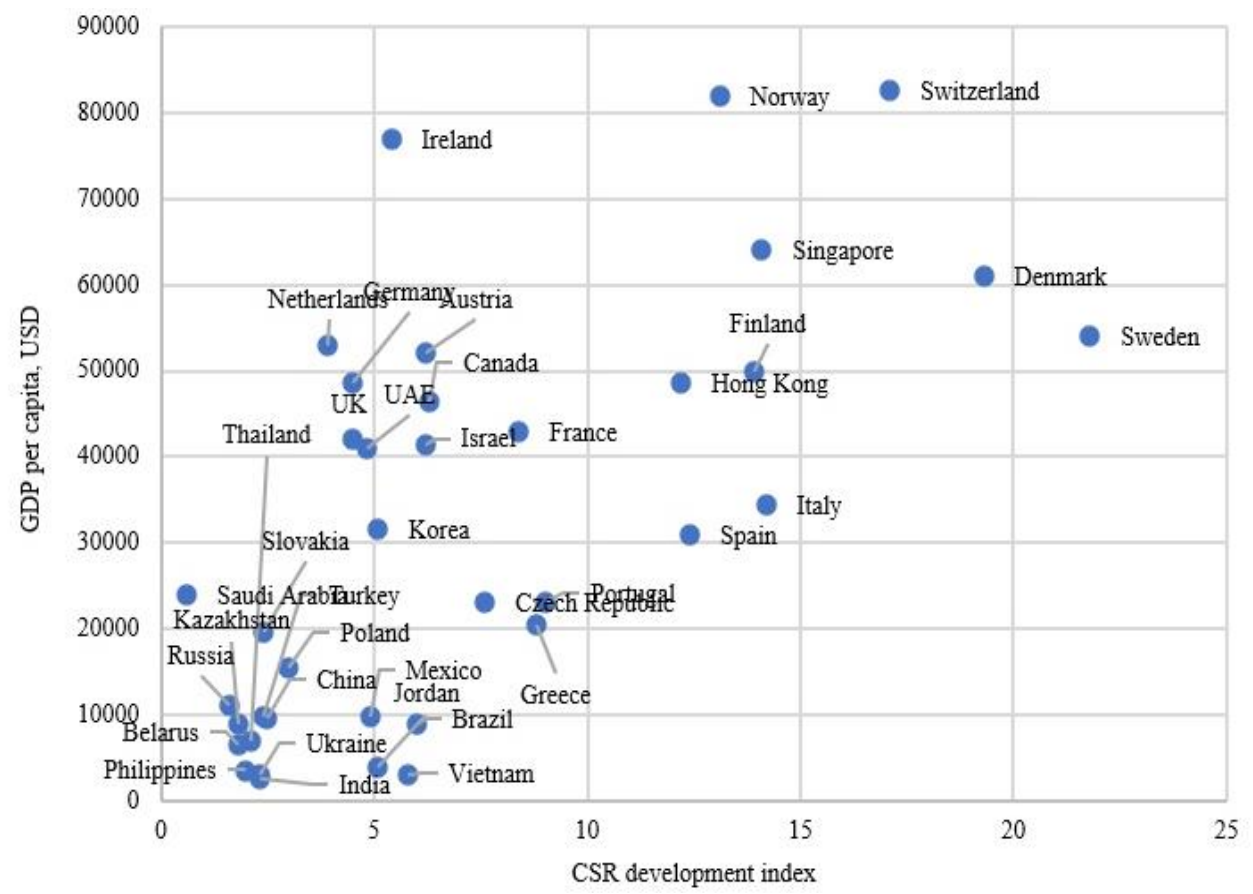

Fig. 2. Dependence of GDP and CSR index [1].

Further, at the micro level, the assessment of CSR efficiency was carried out on the basis of the Goodness Index criterion (Republic of Belarus) According to the results of the 2019 assessment, the highest Goodness Index in the Republic of Belarus was assigned to the following companies:

- large business (more than 500 employees are employed) - assessment of 15 Belarusian enterprises, of which IBA Group 11.8; JSC ASB "Belarusbank" 11.6; Priorbank OJSC 11.2; OJSC "BMZ - managing company of BMK holding" 10.8; OJSC "Belinvestbank" 10.0 and others); the average score of the Good Index for the large business category is 9.5 out of 12 maximum possible (advanced level according to the assessment methodology);

- medium-sized business (100 to 500 employees are employed) - 12 companies were assessed, including the ProLiv group of companies 11.2, SoftTeko 9.9, Qulix Systems CJSC 9.5, Intetiks Bel JLLC 8.8, Limited Liability Company HERE BY MEDIA "8.1 and others; the average score of the Goodness Index for the medium-sized business category is 8.1 (advanced level according to the assessment method) out of 12 maximum possible;

- small business (up to 100 employees are employed) - 14 companies were assessed, of which OOO SAP CIS 9.9, Closed Joint Stock Company HERMITA 9.3, OOO KREITEX 8.0, OOO CSBT SATIO 7.0, OOO BelVneshReklama 7.0; the average score of the Good Index for the small business category is 7.2 out of 12 maximum possible (active level according to the assessment method) [14].

It can be concluded that the assessment of organizations in the Republic of Belarus (41 organizations) using the Goodness Index - assessment of corporate sustainability and business responsibility is quite high.

Another method for assessing the effectiveness of CSR at the micro level is used in Russia based on the Sustainable Development Vector Index. This index is based on the analysis of quantitative information presented in dynamics for a number of indicators that reflect the economic, social and environmental dimensions of sustainable development and CSR (Figure 3). 


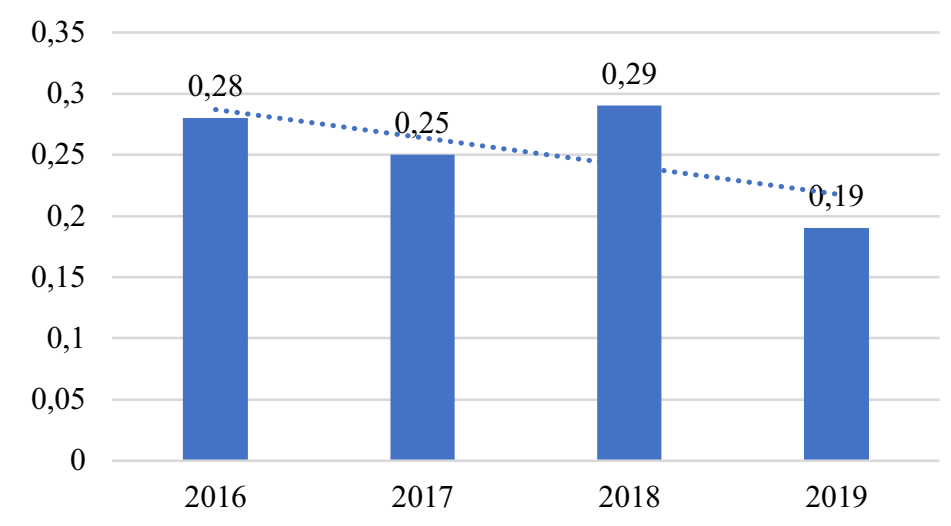

Fig. 3. Average value of the Sustainable Development Vector index in Russia [3].

In accordance with the figure 3, one can observe a negative fact of a decrease in the Sustainable Development Vector Index for the period 2016-2019, by 0.09 .

The leading companies in the Sustainable Development Vector Index - 2019 were 30 companies that showed a positive balance of performance over 3 years (individual index above 0): ALROSA, Gazprom, EVRAZ, EuroChem, Inter RAO, LUKOIL, Metalloinvest, MMK, MTS, NLMK, NOVATEK, Norilsk Nickel, OMK, Polyus, Russian Railways, Rosatom, Rosneft, Rosseti, Rostelecom, RUSAL, Sakhalin Energy, Sberbank, Severstal, SIBUR, AFK Sistema, SUEK, Tatneft, TMK, PhosAgro, FGC UES [3].

An important aspect of the analysis from a practical point of view is the analysis of the areas of CSR activities of companies. The results of the study by the consulting company CIVITTA showed that the priority area of CSR in Belarus is to support vulnerable categories of citizens (68 companies), science and education (46 companies), culture (45 companies) and sports (43 companies) [1].

The main objects of activity of Russian organizations in the field of social responsibility are employees of the organization and their families, attention is paid to the problems of ecology, culture and sports, events that are held within the framework of corporate volunteering.

Based on the analysis of the institutional environment, we can formulate the following problems of implementing CSR strategies in Russia and Belarus [15]:

1. Imperfection of legislation. At present, the legal norms and rules in the field of CSR are not reflected in either the Civil Code or the Tax Code, and there is no legislation on charity in Russia or Belarus.

2. Absence in the current legislation of the countries of the Union State of a clear system for granting tax benefits. Benefits apply only to some types of activities, but their mechanism is not clearly spelled out, which leads to the rejection of charity or the use of "shadow" schemes. Until recently, there was a double taxation of philanthropy.

3. Lack of targeted government policy in the area of corporate social responsibility. Lack of public and media attention to CSR.

4. Weak, uncoordinated and unsystematic support by state structures for the activities of companies in the field of CSR.

5. Lack of understanding by the top management of communication companies of CSR with the possibility of improving market positioning and the role of a positive image.

6. Underestimation by management of the economic benefits of CSR implementation in practice.

7. The conviction of management that CSR diverts resources from solving important tasks of modernizing the economy. 
8. Low level of intersectoral partnership (state-society-business).

9. Lack of mechanisms to educate stakeholders about the benefits of CSR.

At the same time, the external environment is dynamically developing and creates prerequisites for the development of CSR in the countries of the Union State. An analysis of the external environment based on a review of various studies revealed the following trends in the development of the world economy and society, which influence the implementation of a CSR strategy:

1. Development of ICT and digitalization of society, leading to increasing transparency and information accessibility for various stakeholders;

2. Development of network forms of relationships between stakeholders;

3. "Democratization" of knowledge thanks to the Internet.

A significant factor influencing the development of the economy and society as a whole is the activation and penetration of ICT into all spheres of activity and all business processes. The digitalization of the economy provides for the transformation of business as a result of the introduction of digital technologies. In fact, digitalization leads to the development of new CSR methods and tools that can be used in CSR business strategies at the macro and micro levels.

\subsection{Directions for the development of CSR methods and tools in the context of digitalization of the economies of Russia and Belarus}

Based on an analysis of the experience of introducing CSR in Russia and Belarus, as well as barriers and prerequisites, a number of methods can be proposed at the micro and regional levels aimed at enhancing the process of introducing CSR into business activities in the context of digitalization.

$1^{\text {st }}$ direction - Development and distribution of digital communications between government and business for the development of CSR. This direction can be carried out using such tools as:

- Conducting webinars and events for the development of intersectoral social partnership with the participation of a wide range of stakeholders: government, business and society;

- Joint programs with local authorities for additional training and professional retraining of the released labor force - online universities, open universities.

$2^{\text {nd }}$ direction - Introduction of digital tools into public-private partnership (PPP) mechanisms [16], since PPP is one of the most common forms of interaction between business and the state in the framework of CSR. It is proposed to select participants on the basis of an electronic auction for the participation of private business in projects of such a partnership, which will speed up the procedure and make it more transparent.

$3^{\text {rd }}$ direction - Development of interaction between society and business based on digital charity. Charity is especially relevant in the context of the coronavirus pandemic, when the support of medicine and patients is so necessary. The algorithm for creating a digital charity business model can include the following steps:

- Creation of a unified information platform;

- Opening of a charitable foundation;

- Business organization (social support) - creation or purchase of a digital platform, offering users a service, a product (consultations, dispensing drugs, a lottery, a card, etc.);

- Choice of payment system;

- Creating an account on a social network;

- Launching a widget, messages;

- Advertising placement;

- Provision of services, transfer of funds; transfer of benefits, etc .; 
- Evaluation of results.

$4^{\text {th }}$ direction - Organization of volunteer work in the regions, forms of work with youth, interaction with non-profit and religious organizations on the basis of digital platforms for the implementation of CSR principles in the public life of the region. During the period of economic downturn and economic crisis, business initiatives move to the territorial and local levels. New approaches are needed to launch mechanisms for the work of regional partnerships (business - regional and local authorities, civil society organizations) and public-private partnerships in the social sphere and medicine. For example, the creation of such digital platforms - "Anti-Coronavirus", "Healthy Children", etc. All of the above will save jobs, create new and develop existing socially-oriented business models, increase production and sales, protect low-income people, and in general comply with CSR principles.

\section{Conclusions}

Modern Russia and Belarus are characterized by the gradual development of the sphere of corporate governance, an integral part of which is the social responsibility of business to external and internal stakeholders. Its main trends are: the leading role of the corporate sector in the development of CSR; transition from free reporting forms to reports oriented to international standards; enhancing the role of sustainable development as the basis for CSR.

The downturn in economies as a result of the COVID-19 pandemic is forcing businesses to look for new approaches and methods of "survival". At the same time, the external environment provides new opportunities for development - these are digitalization mechanisms. Use of new directions of CSR strategies, such as the development and dissemination of digital communications between government and business for the development of CSR; introduction of digital tools into public-private partnership mechanisms; development of a tool for interaction between society and business based on digital charity; the development in the regions of volunteer work, forms of work with youth, interaction with non-profit and religious organizations in the implementation of CSR principles based on digital platforms, makes it possible to predict the growth of the efficiency of organizations and economies of the Union State as a whole.

The practical significance of the results of the study lies in the possibility of their use by state and regional authorities, as well as by business in CSR strategies, as an integral part of the strategy for sustainable economic development, including for making decisions aimed at increasing the stability and competitiveness of the economies of the Union State.

\section{References}

1. CIVITTA BY conducted a study on the development of CSR companies in Belarus (2019), https://civitta.by

2. Professional competition Brand of the Year in the Republic of Belarus (2019), https://brendgoda.by

3. Indices for Sustainable Development of the Russian Union of Industrialists and Entrepreneurs - 2019: "Responsibility and Openness", "Vector of Sustainable Development", https://media.rspp.ru

4. S. B. Dokholian, Corporate social responsibility of business in Russia and the United State,. Bulletin of the S. Yu. Witte Moscow University. Series 1: Economics and Management, 8 (2014) 
5. M.A. Chernousova, F.R. Eshugova, N.A. Asanova, Naukovedenie Internet magazine, 8 (2) (2016), http://naukovedenie.ru

6. E. A. Sorokina, Trends of corporate social responsibility of business in Russia. Bulletin of the Chelyabinsk State University Economic sciences, 9 (431) (2019)

7. L. S. Kiseleva, CSR standardization: Russian and international realities in the field of sustainable development, https://ria-stk.ru

8. National network of the UN Global Compact in Belarus, http://globalcompact.by

9. National network of the UN Global Compact in Russia, http://www.globalcompact.ru

10. A.A. Okorochkova, Management problems: theory and practice. Measurable Macroeconomics: New Indices for Sustainable Development and Corporate Social Responsibility. Public administration. Electronic bulletin 53 (2015)

11. A.A. Gullo, N.G. Filimonova Analysis of methods for assessing the effectiveness of corporate social responsibility of enterprises, Socio-economic and humanitarian journal of Krasnoyarsk State Agrarian University, 1 (2018)

12. A.P. Zhoidik, Development of methods for assessing corporate social responsibility of Russian companies: Dis. Cand. Econ. Sc.(2015)

13. D.V. Bobrov, Development of methodological support of corporate social policy: Dis. Cand. Econ. Sc. (2015)

14. Index of Goodness in Belarus, https://indexdobra.by

15. Corporate social responsibility in Russia, https://spravochnick.ru

16. G.A. Yasheva Cluster concept of increasing the competitiveness of enterprises in the context of network cooperation and public-private partnership (2010) 